\title{
Minerales y diamantes de conflicto: mecanismo de control y diligencia debida en tiempos de ODS
}

\author{
Minerals and Conflict Diamonds: Control Mechanism \\ and Diligence in Time of Goals \\ M. ${ }^{\text {a Pilar Diago Diago }}$ \\ Catedrática de Derecho Internacional Privado. Universidad de Zaragoza \\ mpdiago@unizar.es
}

\begin{abstract}
Sumario: I. Introducción.-II. Marco y contexto actual de la problemática en tiempos de los objetivos de desarrollo sostenible (ODS).- III. Estudio de los mecanismos legales articulados en las dos normativas de la Unión Europea sobre minerales y diamantes de conflicto 1. El Reglamento 2368/2002 por el que se aplica el sistema de certificación del proceso de Kimberley para el comercio internacional de diamantes en bruto 2. El Reglamento 2017/821 por el que se establecen obligaciones en materia de diligencia debida en la cadena de suministro de estaño, tantalio y wolframio, sus minerales y oro.- IV. Fortalezas y debilidades del sistema de certificación y de la diligencia debida.- V. Prospección de soluciones con especial atención a la implementación de los dos mecanismos.-VI. Consideraciones finales
\end{abstract}

Resumen: el presente estudio analiza exhaustivamente los mecanismos legales elegidos por la Unión Europea para combatir el fenómeno de los minerales y diamantes de conflicto y las violaciones de derechos humanos que le acompañan. Estas importantes normativas marcan la política comercial común actual en estos sectores, lo que afecta directamente a las relaciones privadas internacionales y al comercio internacional; de ahí, la importancia del estudio que desde estos parámetros se presenta con un carácter pionero y abierto. Se presta especial atención al encaje en los ODS y se realiza, además, una prospección de soluciones jurídicas y de implementación que ayuden a esta lucha.

Palabras clave: comercio internacional, Sistema de certificación del Proceso Kymberley, diamantes de conflicto, minerales de conflicto, diligencia debida, Derechos Humanos

Abstract: This study analyzes the legal mechanisms chosen by the European Union to combat the conflict of minerals and diamonds and human rights violations that this entails. These important regulations mark the 
current common commercial policy in these sectors, which directly affects international private relations and international trade; hence the importance of this study, which from these parameters is presented with a pioneering and open character. Special attention is paid to the fit into the SDGs and, in addition, a search is made for legal and implementation solutions that help this fight.

Keywords: The international trade, The Kimberley Process Certification (KP) conflict diamonds, conflict minerals, due diligence, human rights

\section{Introducción}

Este estudio parte de una cruel realidad, la extracción de determinados recursos naturales se relaciona con violaciones reiteradas de Derechos humanos. Estas tiñen de sangre el origen de los diamantes que llegan a las joyerías y de los minerales y metales que forman parte de nuestros ordenadores, teléfonos móviles, coches etc. La extracción y comercialización de los diamantes y de los minerales se relaciona con los conflictos y con las vulneraciones de los Derechos Humanos, configurando un triángulo siniestro que hoy ya no puede ocultarse.

La Unión Europea reacciona ante esta realidad a la que responde la denominación de «diamantes y minerales de conflicto» o de manera más gráfica aún «diamantes y minerales de sangre». La reacción se produce a través de sendas normativas de igual rango, Reglamentos de la Unión, pero de dispar estrategia legislativa. Como se va a tener ocasión de ver en el presente estudio, los mecanismos elegidos para la lucha contra los diamantes y los minerales de conflicto son bien diferentes.

En el primer caso la Unión Europea aprobó el Reglamento 2368/2002 por el que se aplica el sistema de certificación del proceso de Kimberley para el comercio internacional de diamantes en bruto (en adelante Reglamento Kimberley) ${ }^{1}$. El sistema que se instaura es el de Certificación Kimberley acompañado de la prohibición de comercializar con aquellos países que no sean participantes en el mismo.

${ }^{1}$ De 20 de diciembre de 2002 DOUE L 358 de 31de diciembre de 2002 y Reglamento de ejecución de 28 de enero de 2020 por el que se modifica el Reglamento (CE) n. ${ }^{\circ}$ 2368/2002 del Consejo por el que se aplica el sistema de certificación del proceso de Kimberley para el comercio internacional de diamantes en bruto DOUE L27/10 de 31 de enero de 2020 . 
Para los minerales en conflicto ${ }^{2}$, sin embargo, la Unión Europea opta por aprobar el Reglamento 2017/821 por el que se establecen obligaciones en materia de diligencia debida en la cadena de suministro de estaño, tantalio y wolframio, sus minerales y oro (en adelante Reglamento de minerales de conflicto) ${ }^{3}$. El sistema que articula gira en torno a la diligencia debida con un sesgo un tanto voluntarista, que se aleja de la contundencia del Reglamento Kimberley. El Reglamento será plenamente aplicable a partir del 1 de enero de $2021^{4}$.

Obsérvese que estas importantes normativas marcan la política comercial común actual en estos sectores, lo que afecta directamente a las relaciones privadas internacionales y al comercio internacional; de ahí, la importancia del estudio que desde estos parámetros se presenta con un carácter pionero y abierto.

El objeto de investigación se centra en los mecanismos articulados en ambas normativas. Se estudiarán sus fortalezas y debilidades y se tratará de proyectar sistemas de implementación. La finalidad de estos últimos no es otra que, junto con las normativas existentes, contribuir a romper el ya descrito triángulo siniestro.

\section{Marco y contexto actual de la problemática en tiempos de los objetivos de desarrollo sostenible (ODS)}

Tanto los diamantes como los minerales son bienes que regala la naturaleza a diferentes territorios y que son codiciados por todos los demás que

${ }^{2}$ Entiéndase que los minerales de conflicto no son sólo aquellos a los que se dedica el Reglamento. La misma problemática se produce respecto de otros, como ocurre con el cobalto, y que, sin embargo, no han sido incluidos en el ámbito de aplicación material de la normativa.

3 De 17 de mayo de 2017 DOUE L130/1 de 1 de mayo de 2017 y Reglamento delegado 2019/429 de 11 de enero de 2019 por el que se completa el Reglamento (UE) 2017/821 del Parlamento Europeo y del Consejo en lo que respecta a la metodología y los criterios para la evaluación y el reconocimiento de los programas de diligencia debida en la cadena de suministro de estaño, tantalio, wolframio y oro DOUE L 75/59 de 19 de marzo de 2019.

${ }^{4}$ Art. 20 Entrada en vigor y fecha de aplicación

1. El presente Reglamento entrará en vigor a los veinte días de su publicación en el Diario Oficial de la Unión Europea.

2. A excepción de las disposiciones enumeradas en el apartado 3, el presente Reglamento será aplicable a partir del 9 de julio de 2017.

3. 3. El artículo 1, apartado 5, el artículo 3, apartados 1 y 2 , los artículos 4 a 7 , el artículo 8, apartados 6 y 7, el artículo 10, apartado 3, el artículo 11, apartados 1, 2, 3 y 4, los artículos 12 y 13, el artículo 16, apartado 3, y el artículo 17 serán aplicables a partir del 1 de enero de 2021. 
no los tienen. La comercialización a nivel mundial responde, en realidad, a la misma diversidad de la naturaleza. La Unión Europea no dispone de diamantes, pero los consumidores de joyas los reclaman; La Unión Europea no es autosuficiente en numerosos metales y minerales estratégicos y por ello, se recurren a transacciones comerciales por parte de grandes empresas multinacionales para conseguirlos.

Las coordenadas que marcan el negocio de los diamantes y de los minerales de conflicto, en realidad, son las mismas. Los primeros integran un mercado de lujo exigente. Los segundos son recursos imprescindibles para la alta tecnología cuya demanda crece exponencialmente. Su extracción y traslado está marcado por elementos internacionales, que confluyen en la importación a la Unión de los mismos.

Los caprichos de la naturaleza hacen que los países más ricos en estos bienes sean países en desarrollo muy vulnerables que dependen de estos recursos, ya que son sus fuentes más importantes de ingresos y de empleo. Sin embargo, diferentes factores hacen que esta riqueza no se transforme en un crecimiento de su economía y en ellos se cebe la llamada «maldición de los recursos naturales» que se acompaña por el ansia de control sobre los mismos y la falta absoluta de ética y de escrúpulos de aquellos que tienen o quieren alcanzar el control.

Pues bien, la vulnerabilidad de estos países en desarrollo, en relación con el contexto descrito, nos sitúa ante un campo de acción propicio para la proyección de los objetivos de desarrollo sostenible (en adelante ODS) contenidos en la Agenda 2030 sobre el desarrollo sostenible aprobada por la ONU en 20155. A este respecto, el Dictamen del Comité Económico y Social Europeo sobre el tema de «garantizar las importaciones esenciales de la Unión Europea mediante la actual política comercial de la Unión y sus demás políticas relacionadas» ya lo apuntaba ${ }^{6}$. En el Dictamen se insiste en que la sostenibilidad ha de ser fundamental en toda estrategia de la Unión para las importaciones esenciales ${ }^{7}$.

No obstante, esta problemática va mucho más allá de la sostenibilidad y se relaciona con un buen número de objetivos y de metas a los que las normativas de referencia, en su aplicación práctica, pueden ayudar y a los que, por ende, la Unión Europea puede contribuir. Desde la eliminación de la pobreza hasta la protección de la mujer, la defensa del medio ambiente etc.

5 Pagina oficial de Naciones Unidas https://www.un.org/sustainabledevelopment/es/objetivos-de-desarrollo-sostenible/

${ }^{6}$ Dictamen del Comité Económico y Social Europeo DOUE de 6 de marzo de 2014. Ponente Jonathan Peel.

${ }^{7}$ V. en concreto Conclusión y recomendación 1.7 .1 y 3 dedicada al reto estratégico de la sostenibilidad para la Unión Europea. 
Sin ánimo de exhaustividad, algunos de los objetivos más importantes son los que a continuación se señalan.

El objetivo número 2 se resume en «hambre Cero» y cuenta con un pilar importante que es la cooperación para el desarrollo. Los países ricos en diamantes y minerales, aunque pueda resultar paradójico, presentan peores tasas de crecimiento, en ellos se genera corrupción y otras prácticas ilegales. La población sufre la pobreza en países muy ricos en recursos naturales. Sirva como ejemplo la República Democrática del Congo, un país con diamantes, cobre, coltán, cobalto etc. y que, lamentablemente, según datos del Banco Mundial se sitúa entre los países más pobres y que, además, se ha visto azotado recientemente por la epidemia del ébola 8 .

Los dos Reglamentos configuran marcos normativos que se extienden a la cooperación para el desarrollo y al impulso de la buena gobernanza, lo que se espera repercuta en el desarrollo de la economía de los países de origen de los diamantes y minerales. En este sentido, el Reglamento Kimberley señala como la protección de los ingresos procedentes de las exportaciones de diamantes en bruto, contribuirá al desarrollo de los países africanos productores ${ }^{9}$.

Por su parte, el Reglamento de minerales de conflicto reconoce su extensión a políticas de la Unión en materia de cooperación para el desarro$1 \mathrm{lo}^{10}$. Ambas normativas se inscriben, por tanto, en un marco de política comercial común que tiene en cuenta el desarrollo de los países con los que se comercializa y que pueden contribuir de esa manera a la consecución del objetivo 2.

Otro de los objetivos implicados en el resultado de la operatividad práctica de las normativas de referencias, es el objetivo número 8: Trabajo decente y crecimiento económico. En concreto, la meta 8.7 se orienta

8 El Banco Mundial en julio de 2019 movilizo hasta 300 millones dólares para contribuir a detener la epidemia v. Comunicado de prensa N . $^{\circ}$ 2020/018/HD disponible en la página web oficial del Banco Mundial https://www.bancomundial.org/es/news/press-release/2019/07/24/world-bank-mobilizes-us300-million-to-finance-the-ebola-response-in-democratic-republic-of-congo Todos los enlaces web de este estudio fueron comprobados el día 4 de mayo de 2020.

${ }^{9}$ En concreto el Considerando 4 dispone que «Dicho control contribuirá al mantenimiento de la paz y la seguridad internacionales y protegerá los ingresos procedentes de las exportaciones de diamantes en bruto, condición esencial para el desarrollo de los países africanos productores.

10 Considerando 26 «Evitar, mediante la diligencia debida y la transparencia, que los beneficios derivados del comercio de minerales y metales se utilicen para financiar conflictos armados impulsará la buena gobernanza y el desarrollo económico sostenible. Por consiguiente, el presente Reglamento se extiende, de modo accesorio, a ámbitos de las políticas de la Unión en materia de cooperación para el desarrollo, además del ámbito primordial al que se aplica, que se inscribe en el marco de la política comercial común de la Unión». 
a «Adoptar medidas inmediatas y eficaces para erradicar el trabajo forzoso, poner fin a las formas contemporáneas de esclavitud y la trata de personas y asegurar la prohibición y eliminación de las peores formas de trabajo infantil, incluidos el reclutamiento y la utilización de niños soldados, y, de aquí a 2025, poner fin al trabajo infantil en todas sus formas».

La violación de derechos humanos que se produce en torno a la extracción de diamantes y minerales tiene muchas formas, pero un denominador común, la explotación ejercida por grupos armados sobre las poblaciones locales. Los trabajadores son forzados a trabajar en condiciones de semiesclavitud y es muy común el trabajo infantil. Basta recordar la acción del Frente Unido Revolucionario en Sierra Leona y el control de las minas de diamantes en la guerra civil. Situaciones similares se produjeron en Angola, Congo o Liberia. Los mismos hechos se repiten en las zonas de conflicto o de alto riesgo ricas en minerales y en metales ${ }^{11}$.

El efecto de la aplicación de los Reglamentos se programa para tratar de evitar estas violaciones de Derechos humanos. Tanto la certificación Kimberley como el Reglamento de minerales pueden «limpiar» de explotación la extracción de los recursos naturales. Obsérvese, que uno de los efectos colaterales de eliminar el flujo de diamantes de sangre al mercado legal y de aplicar la diligencia debida en la cadena de suministro de los minerales, es el de acabar con la explotación, el trabajo forzoso y el trabajo infantil.

Otro de los objetivos a los que los Reglamentos se espera puedan contribuir, aún de manera indirecta, como consecuencia de su implantación, es el objetivo número 5: lograr la igualdad entre los géneros y empoderar a todas las mujeres y las niñas. En especial, a la meta 5.2 «Eliminar todas las formas de violencia contra todas las mujeres y las niñas en los ámbitos público y privado, incluidas la trata y la explotación sexual y otros tipos de explotación».

Lamentablemente, en muchas ocasiones, las mujeres sufren doblemente la violación de Derechos Humanos por su condición femenina. En las guerras a las que se ha hecho referencia fueron habituales las violaciones y siguen siéndolo en las zonas de conflicto y alto riesgo. El Reglamento de minerales de conflicto reconoce abiertamente esta situación cuando señala que «los grupos armados utilizan con frecuencia las violaciones en masa como estrategia deliberada para intimidar y controlar a las poblaciones locales y preservar así sus propios intereses» ${ }^{12}$.

De nuevo, la operatividad de los Reglamentos conduce en la práctica a evitar estas situaciones a través de sus respectivos mecanismos de control. Por un lado, la presión a los países a través de la exclusión del sistema de

11 V. Considerando 3 Reglamento de minerales de conflicto.

12 V. Considerando 10. 
certificación y la esperada reacción de los mismos. Por otro lado, la presión a los agentes económicos y proveedores, que se espera pueda impedir o mitigar cualitativamente el riesgo, al garantizar que no contribuyen a los conflictos. Entendidos estos en sentido amplio, con la repercusión en las violaciones a las mujeres.

De manera general, las dos normativas son hábiles también para contribuir decididamente al objetivo número 16: paz, justicia e instituciones sólidas. Recordemos que el reto que afrontan las normativas es impedir la financiación de grupos armados (de grupos rebeldes en Kimberley), al establecer un control sobre el comercio de minerales y de metales.

Estas medidas deberían impactar en las instituciones de los países de origen de los recursos, en aras a aumentar su capacidad de prevención de la violencia, la delincuencia y la corrupción. A estos efectos, el Reglamento de minerales de conflicto señala en su Considerando 7 que «las acciones de política exterior y de desarrollo de la Unión también contribuyen a la lucha contra la corrupción local, al refuerzo de las fronteras y a la formación de la población local y sus representantes para que puedan denunciar las irregularidades». ${ }^{13}$

En definitiva, la Unión Europea a través de estos Reglamentos contribuye a la consecución de los objetivos de desarrollo sostenible y, por tanto, a la iniciativa de la ONU de construir un mundo mejor. La trayectoria del Reglamento Kimberley, con clarooscuros, ya ha demostrado su idoneidad para ello. Queda ahora, esperar a la puesta en marcha definitiva del Reglamento de minerales de conflicto para comprobar si cumple las expectativas. De momento, cuenta con anclajes jurídicos y con antecedentes de los que cabe augurar unas buenas perspectivas.

\section{Estudio de los mecanismos legales articulados en las dos normativas de la Unión Europea sobre minerales y diamantes de conflicto}

\section{El Reglamento 2368/2002 por el que se aplica el sistema de certificación del proceso de Kimberley para el comercio internacional de diamantes en bruto}

Antes de abordar el estudio de los mecanismos legales que articula el Reglamento Kimberley, conviene detenerse en una idea que requiere re-

${ }^{13}$ Considerando 7 «Al establecer un control sobre el comercio de minerales procedentes de zonas de conflicto, el presente Reglamento constituye un medio para eliminar la financiación de los grupos armados. Las acciones de política exterior y de desarrollo de la Unión también contribuyen a la lucha contra la corrupción local, al refuerzo de las fronteras y a la formación de la población local y sus representantes para que puedan denunciar las irregularidades». 
flexión. Es común referirse a las gemas en general y a los diamantes en particular, como objeto de protección en el ámbito internacional. La protección, en teoría, vendría motivada por el extraordinario valor que se les concede, y que, de manera directa, como ya se ha expuesto, desencadena la existencia de negocios ilegales, así como la violación reiterada de los Derecho humanos.

Esta apreciación es falsa. No existe normativa internacional protectora de gemas ni de diamantes ${ }^{14}$. Lo que es objeto de protección, y lo es por el Reglamento Kimberley, es el mercado legal de diamantes, de manera que lo que se quiere evitar es el flujo al mismo de diamantes de conflicto. Por lo tanto, la supuesta protección de los diamantes se predica únicamente del mercado legal de compra-venta de diamantes. Esta premisa es fundamental para entender el mecanismo que artículo la normativa para la lucha contra los diamantes de conflicto.

La herramienta base del Reglamento es el Certificado del proceso Kimberley. El Certificado tiene su origen en la Resolución 55/2056 (2000) de Naciones Unidas ${ }^{15}$. En ella se instaba a la Comunidad Internacional a preparar escrupulosa y urgentemente medidas eficaces y pragmáticas para solucionar este grave problema. Estas medidas desembocaron en la creación de un sistema de certificación internacional de diamantes, que se bautizó como sistema de certificación del Proceso Kimberley ${ }^{16}$. El nombre se debe a que fue en esa ciudad en la que se comenzó el Proceso los días 11 y 12 de mayo del año 2000.

${ }^{14}$ M. ${ }^{\text {a }}$ Pilar Diago Diago «Las gemas como objeto de protección en la normativa internacio-

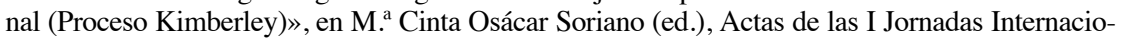
nales sobre Gemología científica en la sociedad actual (Zaragoza, 9-12 de abril de 2008), Universidad de Zaragoza, 2008, 72 a 90. «En realidad no existe normativa internacional protectora de gemas, ni siquiera hay referencias expresas en la normativa dedicada al patrimonio histórico o su recuperación, pese a que las gemas forman parte de las joyas que integran aquel» p. 73 .

$15 \mathrm{~V}$. referencias relativas al sexagésimo segundo periodo de sesiones de la Asamblea General de Naciones Unidas relativas a los diamantes como factor en los conflictos en la página web oficial accesible en https://www.un.org/es/ga/63/plenary/A_diamonds.shtml

${ }^{16} \mathrm{~V}$. el análisis del papel de Naciones Unidas, así como el de la Organización Mundial del Comercio y las excepciones del GATT (con especial atención al principio de superioridad de la OMC) en Enrique J. Martínez Pérez «El comercio de diamantes conflictivos ante el Derecho Internacional» en Comercio Internacional y Derechos Humanos Coord. Antonio Embid Irujo (Madrid: 2007) 247-264 Respecto de la última cuestión v. la referencia a Joost Pauwelyn «compassion or superiority complex?: what to make of the WTO waiver for «conflict diamonds», en Michigan Journal of International Law, (vol. 24, 2003): 1198 y ss (agradezco al autor que me haya proporcionado su trabajo. Este estudio se ha redactado durante el periodo de alarma creado por el COVID 19 que ha obligado a cerrar las bibliotecas por lo que los investigadores no hemos tenido acceso a las obras editadas en papel que no hubiéramos consultado con anterioridad. La generosidad de nuestros colegas, como la del autor, nos ha permitido seguir trabajando, pese a esta eventualidad). 
Todos los países participantes del Proceso Kimberley, utilizan el sistema internacional de certificación y adquieren un compromiso: garantizar que cada remesa de diamantes se acompañe del correspondiente certificado del Proceso. El certificado ha de cumplir una normativa mínima (establecida en la Sección IV) y unos requisitos mínimos (anexo 1).

El Certificado deberá llevar el título «Certificado del Proceso Kimberley» ${ }^{17}$, y la siguiente declaración: Los diamantes en bruto de esta remesa han sido tratados conforme a las disposiciones del sistema de certificación del Proceso Kimberley para diamantes en bruto. ${ }^{18}$ A partir de aquí, el Reglamento de la Unión establece sus propias peculiaridades de implantación del sistema, dentro de su ámbito de aplicación que aparece configurado en el artículo 28 que dispone que se aplicará:

a) en el territorio de la Comunidad, incluido su espacio aéreo, o a bordo de los aviones o barcos bajo la jurisdicción de un Estado miembro,

b) a cualquier nacional de un Estado miembro y a cualquier persona jurídica o cualquier entidad u organismo constituido de acuerdo con la legislación de un Estado miembro.

La delimitación personal del Reglamento relativa a los nacionales de los Estados miembros, debería ser interpretada de manera extensa. Referida, por tanto, a los residentes, personas físicas o jurídicas, con independencia de si ostentarán o no la nacionalidad de un Estado miembro. Algo especialmente importante por lo que se refiere a las personas jurídicas.

Junto a la Certificación, lo más importante es el establecimiento de la prohibición de importación y exportación de diamantes que no cumplan los requisitos Kimberley, al igual que establece el resto de países participantes.

En concreto, el artículo 3 prohíbe la importación de diamantes en bruto a la Comunidad, a menos que reúnan todas las condiciones siguientes:

a) que vayan acompañados de un certificado validado por una autoridad competente de un participante;

b) que sean transportados en contenedores inviolables y los sellos aplicados en la exportación por el citado participante estén intactos;

c) que el certificado defina con claridad la remesa a la que se refiere.

17 V. el sistema de certificación del proceso Kimberley en el Anexo 1 al Reglamento. Para un análisis exhaustivo de su funcionamiento y del funcionamiento del Reglamento de la

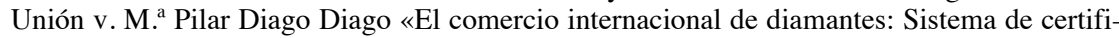
cación del Proceso Kimberley», Cuadernos de Derecho Transnacional (vol. 1, núm. 1, marzo 2009): 72-91.

18 Junto con otras especificaciones como la identificación del exportador y del importador, autoridad que expide el Certificado y la validación del mismo por la autoridad exportadora. 
El sistema de verificación realizado por la autoridad de la Unión Europea, de que las cargas de los contenedores se ajustan a los detalles especificados en el certificado correspondiente, se hará conforme a uno de los dos métodos siguientes (art. 4.5).

a) Aquella abrirá cada uno de los contenedores a fin de proceder a dicha verificación; o

b) determinará los contenedores que se hayan de abrir para proceder a dicha verificación basándose en un análisis de riesgo o sistema equivalente que tenga debidamente en cuenta las remesas de diamantes en bruto.

Se indica, además, que la autoridad ejecutará la verificación sin demora (art. 4.6), si bien, no establece plazos concretos sobre el particular.

Cuando se compruebe que se cumplen las condiciones para la importación de los diamantes, la autoridad lo confirmará en el certificado original y entregará al importador una copia autenticada a prueba de falsificaciones de dicho certificado confirmado ${ }^{19}$. Como se verá más adelante, las falsificaciones van a ser precisamente una de las debilidades del sistema de funcionamiento de la normativa.

Por lo que se refiere a la prohibición de la exportación de diamantes, el artículo 11 establece que:

Se prohíbe la exportación de la Comunidad de diamantes en bruto que no reúnan las dos condiciones siguientes:

a) que vayan acompañados de un certificado comunitario correspondiente, expedido y validado por una autoridad comunitaria competente;

b) que sean transportados en contenedores inviolables sellados de conformidad con lo establecido en el artículo 12;

Por su parte, el mencionado artículo 12 establece las condiciones en las que la autoridad comunitaria podrá expedir un certificado comunitario a un exportador. Para ello se ha tenido que asegurar de que se den las siguientes circunstancias:

a) que el exportador ha proporcionado pruebas concluyentes de que los diamantes en bruto para los cuales se solicita el certificado fueron importados de manera legal de conformidad con las disposiciones del artículo 3;

19 Este procedimiento de confirmación tendrá lugar en un plazo de diez días hábiles a partir de la presentación de certificado (art. 5). En el caso que no se cumplan las condiciones se detendrá la remesa. 
b) que la restante información facilitada en el certificado es correcta;

c) que los diamantes en bruto se importarán al territorio de un participante están destinados efectivamente a llegar al territorio de un participante y

d) los diamantes en bruto se vayan a transportar en un contenedor inviolable.

El sistema de verificación es el mismo que el establecido para el régimen de importación (art. 12.3 ${ }^{20}$.

Una vez visto, aún brevemente, el sistema de funcionamiento del Reglamento, conviene retener que sólo operará respecto de diamantes en bruto que puedan ser considerados diamantes conflictivos. El Reglamento acoge la definición de diamante en bruto y el sistema de certificación Kimberley acoge además la definición de diamante. Estas definiciones son muy importantes pues implican una homologación de descriptores de los diamantes y de su consideración de no tallados. Si bien, la comunidad científica presenta ciertas reservas respecto de la segunda definición, lo que pone el acento en la importancia de contar con la comunidad científica, en este caso gemológica, a la hora de aprobar normativas que inciden en su campo de especialidad.

A lo que aquí interesa, los diamantes en brutos son definidos en el apartado i) del artículo 2 como diamantes no trabajados o simplemente aserrados, exfoliados o desbastados, descritos en el Sistema Armonizado e incluidos en las partidas 710210,710221 y 710231 de la nomenclatura combinada (en lo sucesivo NC);

La pregunta que cabe hacerse, habida cuenta de que el Reglamento sólo se refiere a diamantes en bruto es ¿por qué el peso de la certificación recae sobre los diamantes en bruto y no sobre los diamantes en general? La respuesta la da el hecho de que sólo se puede detectar el origen de esta gema cuando no ha sido manipulada. Como se verá, algo parecido sucede con los metales y los minerales. Una vez que la gema ha sido trabajada, se borra su origen y ya el sistema deviene inoperativo.

Por lo que respecta a los diamantes conflictivos, la definición que ofrece el Reglamento en el apartado h) del mismo artículo 2, remite al sistema de certificación del Proceso Kimberly. La sección I del mismo acoge la definición en los siguientes términos: diamantes en bruto utilizados por los movimientos rebeldes o por sus aliados para financiar conflictos enca-

20 Se prevé, además, que la autoridad comunitaria entregue al exportador una copia autenticada a prueba de falsificación del certificado comunitario que ha validado. El exportador mantendrá accesible cualquier copia durante tres años como mínimo (art.12.4). Se establece un periodo de validez del certificado comunitario no superior a dos meses a partir de la fecha de expedición. En el caso en que los diamantes no sean exportados, el certificado deberá ser devuelto a la autoridad comunitaria que lo expidió. En el caso en que la remesa no reúna las condiciones, esta se detendrá. 
minados a desestabilizar gobiernos legítimos, según los describen las resoluciones del Consejo de Seguridad de las Nacional Unidas (CSNU) vigentes al respecto u otras resoluciones similares del CSNU que puedan adoptarse en el futuro, y tal como los entiende y reconoce la Resolución 55/56 de la Asamblea General de las Naciones Unidas (AGNU) u otras resoluciones similares de la Asamblea que puedan adoptarse en el futuro;

La delimitación que se hace de los diamantes de conflicto, en un principio parecía adecuada para solucionar la problemática concreta respecto de la cual reacciona Naciones Unidas. Sin embargo, se ha quedado corta para poder abordar de manera global, las situaciones que generan el triángulo siniestro ya expuesto y que desborda la actuación de los movimientos rebeldes. Son, en demasiadas ocasiones, los propios gobiernos tiránicos y opresivos los que someten a condiciones de semi esclavitud a su población. En estos momentos es necesaria la evolución del Sistema Kimberley ${ }^{21}$. Esta cuestión se abordará en el apartado IV de este estudio.

\section{El Reglamento 2017/821 por el que se establecen obligaciones en} materia de diligencia debida en la cadena de suministro de estaño, tantalio y wolframio, sus minerales y oro

Una vez examinados los mecanismos que articula el Reglamento Kimberley y que giran en torno al sistema de certificación internacional, con la consiguiente prohibición de importación y exportación de diamantes en bruto, corresponde analizar los mecanismos de los que se va a valer el Reglamento de minerales de conflicto.

Antes de entrar en materia, conviene recordar que a diferencia del Proceso Kimberley que cuenta con un recorrido temporal, que permite sondear sus éxitos y sus fracasos, este nuevo Reglamento no está aún plenamente operativo. Su entrada en vigor se produjo en el año 2017 pero no será plenamente aplicable en todos sus preceptos hasta el 1 de enero de 2021. La razón de este aplazamiento que, pudiera antojarse excesivo, se debe a la implementación que requiere el complejo sistema burocrático que crea.

$\mathrm{Al}$ respecto debe señalarse que ha sido necesario aprobar recientemente el Reglamento delegado 2019/429 de 11 de enero de 2019 por el que se completa el Reglamento (UE) 2017/821 del Parlamento Europeo y del Consejo en lo que respecta a la metodología y los criterios para la evaluación y el reconocimiento de los programas de diligencia debida en la cadena de su-

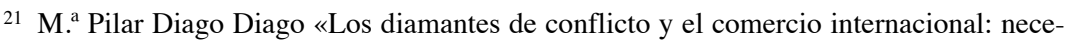
saria evolución del sistema de certificación del proceso Kimberley (PK)» Diario La Ley, No 8364, Sección Tribuna, 29 de (Julio de 2014 Año XXXV):1-4. 
ministro de estaño, tantalio, wolframio y oro $^{22}$. La necesidad de contar con un Reglamento delegado, da cuenta de la complejidad señalada.

El Reglamento de minerales no continúa la senda abierta por el Reglamento Kimberley. Este último sí que ha servido de inspiración para la lucha contra la tala y el comercio ilegal de madera en los países en desarrollo ${ }^{23}$. $\mathrm{Al}$ igual que ocurre con los diamantes y con los minerales de conflicto, los beneficios de aquellas actividades también se utilizan para prolongar conflictos violentos ${ }^{24}$. Es por ello que, a imagen de Kimberley, se aprobó un sistema de licencias que trata de garantizar la legalidad de la tala y de la exportación. Para ello, las importaciones están sometidas a control e inspección en los términos establecidos por el Reglamento 2173/2005 relativo al establecimiento de un sistema de licencias FLEGT, aplicable a las importaciones de madera en la Unión Europea. ${ }^{25}$

Pese a que el sistema de certificación y de licencias, con todas sus dificultades, ha dado buenos resultados y ha demostrado su utilidad para ayudar a frenar los conflictos, la Unión Europea prefiere sondear otro mecanismo muy diferente: la diligencia debida. Si bien, no se trata de una estrategia original pues toma como referencia directa la Ley estadounidense sobre minerales de guerra ${ }^{26}$. En concreto la Sección 1502 de la Ley Dodd

22 V. ref. en nota 3.

23 Tal y como señala Martínez Pérez, «El Comercio de diamantes conflictivos ante el Derecho Internacional», 19 (En la versión original del trabajo).

${ }^{24}$ Comunicación de la Comisión al Consejo y al Parlamento Europeo - Aplicación de las leyes, gobernanza y comercio forestales (FLEGT) - Propuesta de plan de acción de la Unión Europea, doc. COM (2003) 251 final, de 21 mayo de 2003.

${ }_{25}$ Reglamento (CE) núm. 2173/2005 del Consejo, de 20 de diciembre de 2005, relativo al establecimiento de un sistema de licencias FLEGT aplicable a las importaciones de madera en la Comunidad Europea DOUE núm. L 347 de 30 de diciembre de 2005 v. sobre el mismo Brack Duncan «Controlling Illegal Logging and the Trade in Illegally Harvested Timber: The EU's Forest Law Enforcement, Governance and Trade Initiative', en Review of European Community and International Environmental Law, (vol. 14, 2005): 28-38.

${ }_{26} \mathrm{~V}$. Considerando 9 que da cuenta del origen «En sus Resoluciones de 7 de octubre de 2010, de 8 de marzo de 2011, de 5 de julio de 2011 y de 26 de febrero de 2014, el Parlamento Europeo pidió a la Unión que legislase en el sentido de la Ley estadounidense sobre minerales de guerra, es decir, la sección 1502 de la Ley Dodd-Frank de Reforma de Wall Street y Protección de los Consumidores. En sus Comunicaciones de 2 de febrero de 2011, titulada «Abordar los retos de los mercados de productos básicos y de las materias primas», y de 27 de enero de 2012, titulada «Comercio, crecimiento y desarrollo - Una política de comercio e inversión a medida para los países más necesitados», la Comisión anunció su intención de explorar el modo de incrementar la transparencia a lo largo de la cadena de suministro, incluidos los aspectos de la diligencia debida. En la segunda de estas Comunicaciones, y en consonancia con el compromiso asumido en la sesión de mayo de 2011 del Consejo Ministerial de la OCDE, la Comisión abogó también por un mayor apoyo y una mayor utilización de las Líneas Directrices actualizadas de la OCDE para Empresas Multinacionales y de la Guía de Diligencia Debida de la OCDE, incluso entre no miembros de la OCDE.» 
Frank de Reforma de Wall Street y Protección de los Consumidores ${ }^{27}$ que cuenta con una regla de implementación ${ }^{28}$.

El objetivo del Reglamento es eliminar la importación a la Unión Europea de minerales y metales, cuya extracción esté generando violación de los Derechos Humanos. Para ello establece una serie de obligaciones en materia de diligencia debida en la cadena de suministro que recaen en los importadores de la Unión Europea y que se denomina sistema de la Unión ${ }^{29}$. Obsérvese que no se trata de desviar las importaciones a otras zonas libres de conflicto, sino de controlar que las mismas cumplan la diligencia debida. Se trata de lograr, de esta forma, el desarrollo y la paz social en estas zonas, como ya se ha señalado en el apartado relativo a los objetivos de desarrollo sostenible.

Desde esta perspectiva la estrategia es diferente a la de Kimberley. En esta se protege al mercado legal de diamantes y se corta el flujo a él de diamantes conflictivos. Sin embargo, con el sistema de diligencia debida se opera en las mismas áreas de conflicto, tratando de depurar el sistema a través del control que ejercitan los mismos agentes económicos. En realidad, el sistema opera en el plano de la prevención.

La diligencia debida en la cadena de suministro, en consonancia con la Guía de Diligencia Debida de la $\mathrm{OCDE}^{30}$, es definida de manera general en el mismo Reglamento como un proceso continuo, proactivo y reactivo, a través del cual los agentes económicos supervisan y administran sus compraventas con el fin de garantizar que no contribuyan a conflictos o a los efectos negativos de estos ${ }^{31}$.

Más en concreto, el artículo 2 del Reglamento en su apartado d) ofrece la definición de la diligencia debida en la cadena de suministro y la describe como «las obligaciones de los importadores de la Unión de estaño, tantalio y wolframio, sus minerales y oro en relación con sus sistemas de gestión, su gestión de riesgos, las auditorías externas independientes y la

27 La Dodd-Frank Wall Street Reform and Consumer Protection Act (Pub.L. 111-203, H.R. 4173) aprobada por el Congreso de los Estados Unidos en Julio de 2010.

28 Aprobada por la Securities and Exchange Commission (SEC), Final Rule, SEC 17 CFR PARTS 240 and 249b, Conflict Minerals.

${ }^{29}$ Art.1.1.

30 OCDE Due Diligence Guidance for Responsible Supply Chains of Minerals from Conflict- Affected and High-Risk Areas, Recommendation of the Council on Due Diligence Guidance for Responsible Supply Chain of Minerals from Conflict-Affected and Risk Areas. Adopción por el Consejo el 25 de Mayo de 2011, C/MIN(2011)12/FINAL

31 Considerando 11. Sobre diligencia debida y la experiencia francesa v. Antonia Duran Ayago «Sobre la responsabilidad por violaciones graves de los Derechos humanos en terceros países (a propósito de la ley francesa 2017-399, de marzo 2017, relativa al deber de vigilancia de las empresas matrices sobre sus filiales)», AEDIPr. (T.XVIII, 2018): 323-348. 
comunicación de información con el fin de identificar y abordar los riesgos reales y potenciales vinculados a las zonas de conflicto o de alto riesgo para impedir o reducir los efectos negativos asociados a sus actividades de abastecimiento».

A su vez, la norma ofrece en el apartado c) la definición de lo que se debe de entender por cadena de suministro de minerales «el sistema de actividades, organizaciones, actores, tecnologías, información, recursos y servicios que opere en el desplazamiento y procesamiento de los minerales desde el lugar de extracción hasta su incorporación en el producto final».

Los minerales objeto de control son el estaño, tantalio y wolframio, sus minerales y oro (art. 2). Quedan, por tanto, fuera el cobalto o cobre y los diamantes. La última exclusión es lógica ya que se cuenta con el Reglamento Kimberley. Más dudosa es la exclusión del cobalto o del cobre, dado que, sobre todo, el primero es un mineral estratégico de importancia creciente $^{32}$.

El famoso coltán está incluido entre los minerales de conflicto, pese a las informaciones que en su día se divulgaron ${ }^{33}$. Al respecto, debe tenerse en cuenta que el término «coltán» no es el de un mineral aprobado y su uso está extendido especialmente en la zona de África y se está expandiendo. Su inclusión viene dada porque están incluidas las fuentes del metal tántalo.

El Reglamento reacciona ante los minerales y metales de conflicto. Estos son los originarios de zonas de conflicto o alto riesgo, extraídos en unas condiciones que impliquen violación de los Derechos Humanos. El Reglamento define las zonas de conflicto o alto riesgo como «zonas que se encuentren en situación de conflicto armado o de posconflicto frágil, así como las zonas con gobiernos o seguridad precarios o inexistentes, como los Estados fallidos, y con vulneraciones generalizadas y sistemáticas del Derecho internacional, incluidas las violaciones de los derechos humanos». ${ }^{34}$

${ }^{32}$ Silvia Vilar González señala que la exclusión también del jade o de los rubíes puede deberse a presiones de los lobbies en Bruselas Silvia Vilar González «Iniciativas para la erradicación de los abusos de los derechos humanos asociados al negocio de las «minas de sangre» en Usos sostenibles de la tierra y desarrollo humano Coord Manuel Rivera Mateos (Sevilla 2029),104-124 en concreto p. 115 En especial respecto de la exclusión del cobalto v. Nerea Magallón Elósegui «Comercio de minerales y Derechos humanos: el Reglamento 2017/821: hacia un abastecimiento responsable de los minerales procedentes de las zonas de conflicto en Europa» en Anuario de los cursos de Derechos humanos de Donostia-San Sebastián Dir. Juan Soroeta Liceras (Valencia 2019), 152.

33 V. un ejemplo en Comparte en Facebook Comparte en Twitter

http://www.lavanguardia.com/politica/20170316/42927634741/el-pe-aprueba-normacontra-minerales-de-conflicto-que-no-incluye-diamantes.html

34 Artículo 2. 
A diferencia de lo que ocurre con la normativa estadounidense que se refiere en concreto a la República Democrática del Congo y países limítrofes, el Reglamento no ofrece un listado de estas zonas. Si bien, el artículo 14 establece directrices al respecto. En concreto señala que «Para aportar claridad, seguridad y coherencia a las prácticas de los agentes económicos, en particular las pymes, la Comisión, consultando al Servicio Europeo de Acción Exterior y a la OCDE, elaborará directrices no vinculantes, en forma de manual para los agentes económicos en el que se explique el mejor modo de aplicar los criterios para la determinación de zonas de conflicto o de alto riesgo. Dicho manual se basará en la definición de zonas de conflicto o de alto riesgo del artículo 2, letra f), del presente Reglamento y tendrá en cuenta la Guía de Diligencia Debida de la OCDE en la materia, incluidos otros riesgos relacionados con la cadena de suministro que desencadenen señales de alerta definidas en los suplementos correspondientes de dicha Guía»

La concreción relativa a los grupos armados y fuerzas de seguridad (recuérdese que se trata de que tengan menos oportunidades de comercializar con los minerales) se hace a través del Anexo II de la Guía de Diligencias Debida de la OCDE, tal y como establece el apartado g) del artículo 2 de la norma.

El Reglamento establece cuatro tipos de obligaciones que recaen en todos los importadores de la Unión Europea, con independencia de que se abastezcan o no, de minerales o metales que procedan de zonas de conflicto o alto riesgo. Teniendo en cuenta la enorme carga burocrática que ello implica, quizás esta medida debería haberse limitado a sólo los importadores que se abastezcan de las zonas de conflicto, en cuanto que la problemática se suscita en ellas.

Cabe destacar, y esto juega como una debilidad del sistema, que sólo opera respecto de importadores directos de minerales. Ello se deduce de la propia definición ya anotada relativa a la cadena de suministro de minerales. Como puede comprobarse, la cadena termina con la incorporación en el producto final. Esto es, las empresas que importan los componentes ya facturados, que se dedican, precisamente, a la facturación y venta del producto final, quedan fuera del sistema de la Unión ${ }^{35}$.

También quedan fuera tal y como establece el artículo 1.3 los importadores de la Unión de minerales o metales cuando el volumen anual de sus importaciones de cada uno de los minerales o metales de que se trate sea in-

35 Así lo describe Magallón Elósegui «Comercio de minerales y Derechos humanos: el Reglamento 2017/821: hacia un abastecimiento responsable de los minerales procedentes de las zonas de conflicto en Europa» en Anuario de los cursos de Derechos humanos de Donostia-San Sebastián» 156 como una de las grandes debilidades del Reglamento 
ferior al mínimo respectivo establecido en el anexo $\mathrm{I}^{36}$. Esta prescripción supone otro límite a su ámbito de aplicación. Al respecto debe señalarse que este límite se aparta de lo dispuesto en la guía para la interpretación de los principios rectores sobre empresas y D. Humanos ${ }^{37}$ que, precisamente, se refiere a las empresas de minerales, en lo referente a la relación del tamaño de la empresa con su responsabilidad en el respeto de los Derechos Humanos.

La guía parte de este ejemplo «una empresa pequeña con menos de diez empleados que se dedique al comercio de minerales o metales desde una zona caracterizada por los conflictos y las violaciones de los derechos humanos vinculados a la minería tiene un alto perfil de riesgo en materia de derechos humanos. Sus procesos y políticas destinados a velar por que no se vea involucrada en esas violaciones habrán de ser proporcionales a ese riesgo».

$\mathrm{Al}$ respecto la guía continúa señalando que «en el comentario del Principio Rector 17 se examina más detalladamente cómo el asesoramiento especializado externo y la utilización de un conjunto de recursos comunes pueden ayudar a todas las empresas, y particularmente a las pequeñas y medianas, a observar un proceso de debida diligencia en materia de derechos humanos que sea a la vez eficaz y proporcional a sus riesgos relacionados con los derechos humanos y a sus recursos»

A estas exclusiones hay que añadir que el Reglamento no se aplica tampoco a los minerales reciclados. Como ocurría en Kimberley el Sistema de la Unión debe operar sobre minerales y metales «puros», puesto que cuando se someten a manipulación se borran sus huellas y entonces, el sistema deja de ser operativo ${ }^{38}$.

Una vez delimitado el concreto ámbito de aplicación del Reglamento, corresponde ahora hacer un acercamiento a los cuatro tipos de obligaciones ya mencionadas ${ }^{39}$.

${ }^{36}$ El precepto continúa señalando que «Todos los volúmenes mínimos se fijan en un nivel que garantiza que, para la gran mayoría, sin bajar del $95 \%$, de los volúmenes totales importados a la Unión de cada mineral o metal bajo el código de la nomenclatura combinada se hayan de cumplir las obligaciones impuestas a los importadores de la Unión en virtud del presente Reglamento.»

${ }^{37}$ Guía para la interpretación de los principios rectores «La responsabilidad de las empresas de respetar los Derechos humanos» Naciones Unidas, Nueva York y Ginebra 2012 disponible en https://www.ohchr.org/Documents/Publications/HR.PUB.12.2_sp.pdf p. 24.

$38 \mathrm{~V}$. Considerando 16.

39 V. estas obligaciones en mi trabajo M. ${ }^{\text {a }}$ Pilar Diago Diago «El control del comercio internacional de los minerales de conflicto: Reglamento (UE) 2017/831 por el que se establecen obligaciones en materia de diligencia debida en la cadena de suministro de estaño, tántalo y wolframio, sus minerales y oro» en Diario La Ley n. 90999 (2017): 12-19 en las que adelanto lo que entiendo son debilidades del sistema del Reglamento. 
Las primeras son obligaciones relativas al sistema de gestión (art.4). Estas obligaciones consisten, en especial, en «aplicar una cadena de custodia o un sistema de trazabilidad de la cadena de suministro que aporte una información determinada sobre los minerales o metales»: descripción del mineral, nombre y dirección del proveedor, país de origen de los minerales etc.

Cuando los minerales o metales sean originarios de zonas de conflicto o de alto riesgo se prevé una información adicional como «la mina de origen de los minerales, los lugares en los que los recursos se consolidan, comercializan y procesan y los impuestos, tasas y cánones pagados» (art. $4 \mathrm{f}$ ) y g).

Téngase en cuenta al respecto, la dificultad en ocasiones de verificar la información sobre el origen del mineral. Una vez que se produce su transformación, como ya se ha advertido, es casi imposible rastrear su origen, de ahí, la importancia de conseguir esta información en las fases iniciales

Las segundas son obligaciones en materia de gestión de riesgos (art.5). Los importadores estarán obligados a detectar y evaluar los riesgos de efectos negativos en su cadena de suministro. En su caso, deberán aplicar una estrategia para afrontar los riesgos, que bien puede ser la de ejercer presión sobre los proveedores que «más eficazmente pueden impedir o reducir el riesgo» art. 5 b) ii). En este sentido, ninguna presión mayor que las que señala la normativa: suspensión temporal del comercio o incluso romper la relación con el proveedor tras intentos fallidos de reducción del riesgo.

Las terceras obligaciones establecidas por el Reglamento se refieren a auditoría externa (art.6). Los importadores de la Unión deben llevar a cabo auditorías externas por medio de terceros independientes. Estarán exentos de esta obligación aquellos importadores que faciliten «pruebas sustanciales, incluidos informes de auditorías externas, de que todas las fundiciones y refinerías de su cadena de suministro cumplen el Reglamento». Con la precisión que introduce en apartado segundo del art. 6 «El requisito de las pruebas sustanciales se considerará cumplido cuando los importadores de la Unión de metales demuestren que se abastecen exclusivamente de las fundiciones y refinerías incluidas por la Comisión en una lista de conformidad con el artículo $9 »^{40}$.

$40 \mathrm{Al}$ respecto el Reglamento explica la importancia de las refinerías y fundiciones y la obligación de someterse a auditoria «Las fundiciones y refinerías son un eslabón importante de las cadenas de suministro mundiales de minerales, pues suelen ser la última fase en la que puede garantizarse la diligencia debida al recoger, comunicar y verificar información sobre el origen del mineral y la cadena de custodia. Después de esa primera fase de transformación, a menudo se considera imposible rastrear el origen de los minerales. Lo mismo sucede con los metales reciclados, que han pasado incluso por más fases en el proceso de transformación. Por tanto, una lista de la Unión de las fundiciones y refinerías a escala mundial responsables podría aportar transparencia y seguridad a los agentes económicos de las fases finales por lo 
Esta prescripción requiere de una mayor reflexión relativa al efecto que quiere producir. En realidad, la elaboración de la lista de fundiciones y refinerías a escala mundial responsables, tiene como finalidad última, la de conseguir que los importadores de la Unión Europea se abastezcan exclusivamente de ellas. Ello explica, que la exención opere como un incentivo. Al margen de ello, queda pendiente el trabajo de certificación de minas in situ y la aprobación de medidas de acompañamiento ${ }^{41}$.

Las cuartas obligaciones se refieren a la comunicación (art. 7) y tienen una gran importancia de cara a las medidas de implementación que se van a formular en este trabajo. Las auditorías externas deberán ser puestas a disposición de las autoridades competentes de los Estados miembros. Los importadores pondrán a disposición de sus compradores inmediatos de las fases finales la información obtenida en el cumplimiento de la diligencia debida con «la debida atención al secreto comercial y otras cuestiones ligadas a la competencia de mercado». Es evidente que esta precaución sesgará la información, con lo que la obligación queda un tanto diluida ${ }^{42}$, lo cual apunta a otra debilidad del sistema.

Por último, se exige que los importadores de la Unión Europea informen anualmente al público sobre sus políticas de diligencia debida en la cadena de suministro y sus practicas al respecto. La información la deberán de proporcionar con la mayor amplitud posible, también por internet.

que se refiere a las prácticas de diligencia debida en la cadena de suministro. De conformidad con la Guía de Diligencia Debida de la OCDE, los agentes económicos de las fases iniciales, como las fundiciones o las refinerías, deben someterse a una auditoría externa independiente en relación con sus prácticas de diligencia debida en la cadena de suministro, también con vistas a incluirlos en la lista de fundiciones y refinerías a escala mundial responsables» Considerando 16.

${ }^{41}$ En esta línea Magallón Elósegui «Comercio de minerales y Derechos humanos: el Reglamento 2017/821: hacia un abastecimiento responsable de los minerales procedentes de las zonas de conflicto en Europa» nota 49 p. 165 señala que «El Reglamento sobre minerales debe ir acompañado de las medidas de acompañamiento en el lugar de producción para garantizar la mejora de las condiciones de los trabajadores en las minas. En este sentido para que realmente sea efectivo el cambio en las políticas de suministro y abastecimiento, se debe insistir en las medidas de acompañamiento, tal y como pone de relieve, un informe realizado por The European Network for Central Africa (EurAc) «Accompanyng Measures in the EU Regulation on the responsable sourcing of minerals», marzo 2017. El Parlamento Europeo intento introducir un artículo 15 a) en la Propuesta del Reglamento mediante la enmienda no 55 en el que interpelaba a establecer un Programa por la Comisión de medidas de acompañamiento de cara a asegurar la eficacia del Sistema de la Unión, pero finalmente no salió adelante, P8_TA (2015) 0204».

42 V. esta cuestión en Diago Diago «El control del comercio internacional de los minerales de conflicto: Reglamento (UE) 2017/831 por el que se establecen obligaciones en materia de diligencia debida en la cadena de suministro de estaño, tántalo y wolframio, sus minerales y oro» p. 15 . 
$\mathrm{Al}$ calor de la normativa estadounidense es habitual encontrar información sobre las prácticas comerciales relativas a los minerales de conflicto y al cumplimiento ético y legal de las prácticas comerciales por parte de las empresas $^{43}$. Esta información redunda en el buen prestigio de aquellas, lo que resulta especialmente importante en el ámbito comercial.

\section{Fortalezas y debilidades del sistema de certificación y de la diligencia debida}

Como se ha tenido ocasión de comprobar las dos normativas de la Unión Europea reaccionan ante un mismo hecho: las violaciones de los Derechos Humanos en las zonas ricas en recursos y que se relacionan con su explotación. En el preámbulo del sistema de certificación Kimberley se reconoce abiertamente «los efectos devastadores de los conflictos alimentados por el tráfico de esos diamantes sobre la paz y la seguridad de las poblaciones de los países afectados, así como las graves y sistemáticas violaciones de los derechos humanos perpetradas en esos conflictos» ${ }^{44}$.

Por su parte, el Reglamento de minerales lo hace en su Considerando tercero donde se afirma que «Las violaciones de los derechos humanos son habituales en zonas de conflicto o de alto riesgo ricas en recursos y pueden consistir en trabajo infantil, violencia sexual, desapariciones de personas, reasentamientos forzosos y destrucción de enclaves importantes desde el punto de vista cultural o ritual».

Las dos normativas son pioneras y establecen, por primera vez, mecanismos que tratan de romper el nexo entre conflictos y explotación de minerales. En el Reglamento Kimberley se adoptan medidas contra el comercio ilícito para romper los vínculos entre los diamantes en bruto y los conflictos $\operatorname{armados}^{45}$. En el Reglamento de minerales se opta por el abastecimiento responsable, promoviendo prácticas de diligencia debida orien-

43 Valga como ejemplo la información contenida en la página web de Komatsu https:// mining.komatsu/es/compañ\%C3\%ADa/nuestra-compañ\%C3\%ADa/how-we-do-business/declaración-de-minerales-de-conflicto o la declaración sobre su política sobre minerales de conflicto de HermanMiller disponible en https://www.hermanmiller.com/es_lac/legal/conflictminerals/

44 Anexo 1 del Reglamento

45 V. en concreto, Considerando 2 del Reglamento Kimberley que recuerda que «en su reunión celebrada en Göteborg en junio de 2001, el Consejo Europeo adoptó un programa para la prevención de enfrentamientos, que establece, entre otras cosas, que los Estados miembros y la Comisión adoptarán medidas contra el comercio ilícito de mercancías de gran valor». 
tadas a la ruptura de aquel nexo. Con ello, ambos instrumentos pretenden contribuir a la paz y a la seguridad ${ }^{46}$ y con ello, contribuyen a la consecución de varios objetivos de desarrollo sostenible y a sus metas desde la Unión Europea.

Estas normativas tienen un alcance de primer orden en el ámbito comercial internacional. Téngase en cuenta que las dos generan una política comercial común de la Unión Europea. El Reglamento Kimberley, además, enlaza con la política comercial del resto de países participantes lo que hace que, en realidad, su esfera de actuación sea a nivel mundial. El Reglamento de minerales de conflicto es más modesto, pero también aspira a un efecto mayor, si se tiene en cuenta la elaboración de la lista de fundiciones y refinerías a escala mundial responsables y el efecto que se espera conseguir y que ya se ha analizado.

Ahora bien, como se ha tenido ocasión de analizar, los dos Reglamentos utilizan mecanismos muy diferentes. El Reglamento Kimberley apuesta por proteger el mercado legal de diamantes en bruto. Lo hace a través del sistema de certificación y de las prohibiciones de exportar e importar diamantes que procedan de países no participantes. El efecto es contundente, se crea un mercado legal de diamantes que impide el flujo de diamantes de conflicto.

Esta normativa entraña una clara limitación al principio de libre comercio a escala mundial. Constituye un auténtico hito en la Historia del Derecho contemporáneo, porque con ella se va mucho más lejos que con otras medidas que con frecuencia se han tomado en este ámbito, como son los vetos a las relaciones comerciales con otros países ${ }^{47}$. Esta limitación merece la pena si se tiene en cuenta que, en gran medida, el Sistema de certificación Kimberley ha logrado sus objetivos. Gran parte de los diamantes de sangre han dejado de «colarse» en el mercado legal y países de origen de estas preciosas gemas, son parte de Kimberley y aseguran el cumplimiento de las normativas.

Ahora bien, no se trata de un éxito completo. Por un lado, se han detectado falsificaciones en los certificados. Pese a que el certificado del Proceso Kimberley es definido como un documento a prueba de falsificaciones, con

${ }^{46}$ Considerando 1 del Reglamento de minerales «En las zonas de conflicto o de alto riesgo, los recursos naturales minerales, a pesar de que entrañan un gran potencial para el desarrollo, pueden ser causa de disputas si los ingresos que producen alimentan el brote o la continuación de conflictos violentos, lo que socava los esfuerzos en pos del desarrollo, la buena gobernanza y el Estado de Derecho. En dichas zonas, romper el nexo entre los conflictos y la explotación ilegal de minerales es un elemento esencial para garantizar la paz, el desarrollo y la estabilidad».

47 Diago Diago «El comercio internacional de diamantes: Sistema de certificación del Proceso Kimberley», 74. 
un formato especial, que califica una remesa de diamantes en bruto de conforme con las exigencias del sistema de certificación ${ }^{48}$, la praxis ha demostrado que la falsificación existe. Amberes alertó sobre la falsificación de certificados Kimberley en diciembre de $2015^{49}$. En el año 2016 las autoridades del Proceso Kimberley en Sierra Leona activaron la alerta sobre un envío a Hong Kong de diamantes en bruto con certificado falsificado ${ }^{50}$.

Por otro lado, siguen existiendo diamantes de conflicto que penetran en el mercado, incumpliendo el sistema Kimberley. Valga como ejemplo que atestigua esta realidad la sentencia del Tribunal General de la Unión Europea en el asunto Badica y Kardiam contra el Consejo de la Unión Europea $^{51}$. El supuesto de hecho de la Sentencia se refiere a la suspensión temporal en mayo de 2013 de la República Centroafricana del sistema de certificación del Procedimiento Kimberley y al hecho de que las empresas Badica y Kardiam continuaron comprando diamantes que eran objeto de tráfico ilegal desde dicha región. Sus beneficios sirvieron para financiar a los grupos armados de los antiguos Seleka y anti-balaka que operaban en dicha zona ${ }^{52}$.

No obstante, la mayor debilidad que presenta Kymberley es su no evolución. La realidad demuestra que siguen produciéndose violaciones de Derechos Humanos relacionadas con la extracción y comercialización de los diamantes en bruto y que esas violaciones no se generan por la acción de grupos rebeldes, tal y como están definidos en el Proceso. Los conflictos son generados, en ocasiones, por los propios gobiernos tiránicos. Precisamente, la crisis más importante del Procedimiento tuvo lugar en diciembre de 2011 cuando la ONG Global Witness decide abandonar Kymberley ${ }^{53}$, al no producirse una evolución para acabar con los vínculos existentes entre diamantes-violencia-tiranía ${ }^{54}$.

48 V. Anexo I Sección I del Reglamento.

49 http://www.goldandtime.org/noticia/80832/Goldtime/Amberes-alerta-sobre-la-falsificacion-de-certificados-Kimberley-desde-Sierra-Leona.html

${ }^{50} \mathrm{http} / /$ www .goldandtime.org/noticia/81048/Goldtime/Falso-Certificado-Kimberley-dediamantes.html

51 Asunto T-619/15 (Badica y Kardiam/Consejo) ECLI:EU:T:2017:532

52 V. análisis de esta Sentencia en Vilar González «Iniciativas para la erradicación de los abusos de los derechos humanos asociados al negocio de las «minas de sangre» 116-118.

53 Charmian Gooch (2011). Global Witness leaves Kimberley Process, calls for diamond trade to be held accountable. Global Witness. Press Release, Dec. 2, 2011. Disponible en https://www.globalwitness.org/es/archive/global-witness-leaves-kimberley-process-calls-diamond-trade-be-held-accountable/

${ }^{54}$ El detonante lo produjo la situación de Zimbabue Jerbi, S. Evaluación del papel de las iniciativas de múltiples actores en la promoción del programa de empresas y derechos humanos. International Review of the Red Cross, n. 887 (2012): 29-50 p. 43. 
La solución debería pasar por la evolución del Proceso Kymberley por la que ya he abogado en otros estudios ${ }^{55}$. En especial, sería necesaria una redefinición de «diamantes de conflicto». Bastaría para ello con ampliar la definición e incluir los diamantes cuya comercialización da lugar a violación de Derechos humanos, siendo indiferente de dónde provengan aquellos: movimientos rebeldes o «gobiernos legítimos». Desde esta perspectiva, resulta mucho más acertado el funcionamiento del Reglamento de minerales, que opera respecto de zonas de conflicto y alto riesgo. Como ya se ha expuesto, su definición es amplia y acoge a las zonas con gobiernos o seguridad precarios o inexistentes, como los Estados fallidos, y con vulneraciones generalizadas y sistemáticas del Derecho internacional, incluidas las violaciones de los derechos humanos ${ }^{56}$. Esa misma amplitud debería acogerse en Kimberley dentro de su más que necesaria evolución.

Por su parte, el Reglamento de minerales de conflicto utiliza, como se ha expuesto, mecanismos muy diferentes. La diligencia debida juega en el plano de la prevención y se apoya en este «mecanismo extrajudicial» como método principal de acción. Se transita de esta manera por los caminos marcados por la OCDE, que como es sabido, se asientan en recomendaciones no vinculantes.

El hecho de que no tenga aún recorrido temporal hace difícil que se pueda vaticinar el éxito de su implantación. Sin embargo, su inspiración directa en la Ley estadounidense y el seguimiento de esta en la práctica, hace posible prever que tendrá una aceptable implementación y seguimiento, al igual que ya ha ocurrido con la Sección 1502 de la Ley Dodd-Frank.

Quizás una de sus principales fortalezas es que, a diferencia de Kimberley, se trabaja con zonas de conflicto, si bien estableciendo cierto control sobre el comercio, que no llega a asemejarse al creado por Kimberley. Desde este ángulo, el Reglamento resulta muy interesante para contribuir al desarrollo de las zonas de conflicto y alto riesgo. Piénsese que, en el caso de los diamantes, la exclusión de un país participante puede conducir a extremar la pobreza de sus ciudadanos, ya que una gran parte de ellos sobrevive con los ingresos de las minas.'

Ahora bien, su estudio detallado permite revelar ciertas debilidades, algunas de las cuales ya se han mencionado en este trabajo. Como apreciación general cabe decir, que todo el sistema se asienta en una especie de auto regulación voluntaria, en el sentido en que los importadores deben velar ellos mismos por el cumplimiento de las obligaciones. En esta línea

55 Diago Diago «El control del comercio internacional de los minerales de conflicto: Reglamento (UE) 2017/831 por el que se establecen obligaciones en materia de diligencia debida en la cadena de suministro de estaño, tántalo y wolframio, sus minerales y oro»

56 Art. 2 f) 
cabe señalar, que el mismo régimen de sanciones aplicables a las posibles infracciones, no está siquiera especificado ${ }^{57}$.

Desde apreciaciones más concretas, también su ámbito de aplicación plantea dudas ¿Por qué no se ha incluido el cobalto o el cobre? Y ¿por qué se ha excluido a las empresas que importan productos en los que ya se ha incorporado el material? ¿por qué, además, han quedado fuera importadores de la Unión Europea de minerales y metales cuyo volumen anual no llega al mínimo marcado por la normativa? Y en otro orden de cuestiones ¿por qué el deber de comunicación se ha visto diluido con la atención al secreto comercial y a otras cuestiones ligadas a la competencia del mercado?

Los agentes económicos van a tener que afrontar una gran carga administrativa y burocrática que puede repercutir en la propia competitividad de las empresas. Ello ocurrirá cuando se eleve el coste del abastecimiento, como consecuencia del cumplimiento de las obligaciones impuestas por el Reglamento. Baste recordar las relativas a la gestión de riesgos o las auditorías. Estas consecuencias serán mayores para las medianas y pequeñas empresas y es por ello, que se ha previsto que disfruten de una ayuda técnica y financiera para facilitar la aplicación de la normativa ${ }^{58}$.

Existe además un riesgo que debería minimizarse. La carga de gestión y de comunicación que implica el proceso de diligencia debida, podría convertirse en un mero cumplimiento de requisitos formales. Sin una implicación sustantiva de los agentes económicos el proceso podría quedar muy diluido ${ }^{59}$.

57 Así el «artículo 16 dispone que los Estados miembros establecerán el régimen de sanciones aplicable a cualquier infracción del presente Reglamento, lo que significa que puede haber variaciones entre ellas. Pero a ello hay que añadir que las autoridades competentes de los Estados miembros no tienen, en realidad, competencia para imponer sanciones a los importadores. El citado precepto sólo establece que «en caso de infracción, las autoridades competentes de los Estados miembros notificarán las medidas correctoras que deberá adoptar el importador de la Unión» (Esta es una de las cuestiones que la Comisión evaluará en la revisión del Reglamento (art. 17)) Diago Diago «El control del comercio internacional de los minerales de conflicto: Reglamento (UE) 2017/831 por el que se establecen obligaciones en materia de diligencia debida en la cadena de suministro de estaño, tántalo y wolframio, sus minerales y oro» p.14.

58 Programa COSME v. Reglamento UE n. ${ }^{\circ}$ 1287/2013.

59 Así lo apunta Olga Martín-Ortega «Europa se enfrenta (por fin) al resto de los minerales conflictivos: El Reglamento 2017/821» Revista General de Derecho Europeo $(45,2018)$ : 276-298 en concreto p. 298 De la misma autora en prensa ref nota 57 «Due Diligence, Reporting and Transparency in Supply Chains: The UK Modern Slavery Act», en BONFANTI (ed), Business and Human Rights: International Law Challenges, European Responses (Routledge, Oxon, 2018). 


\section{Prospección de soluciones con especial atención a la implementación de los dos mecanismos}

Como se ha tenido ocasión de comprobar en este estudio, las dos normativas pioneras en sus respectivos sectores de referencia, presentan fortalezas y debilidades. El Sistema Kimberley, ha contribuido a reforzar el mercado legal de diamantes en bruto, si bien no lo ha limpiado del todo. El Reglamento de minerales de conflicto, cuenta con un antecedente directo que permite augurar éxito en su implantación, si bien, de base, parte con puntos débiles que es de presumir afecten al grado de consecución de sus objetivos.

Pues bien, una perspectiva global nos sitúa en un plano en el cual puede realizarse una prospección de otras soluciones, a la problemática que genera el contexto base al que responden los dos Reglamentos. La primera idea enlaza con la posibilidad de ampliación de los respectivos ámbitos de aplicación de sendas normativas.

Kimberley reúne las características necesarias para convertirse en un procedimiento estándar del comercio internacional para materias primas problemáticas ${ }^{60}$. De hecho, los conflictos originados por la extracción de diamantes, son exactamente los mismos que se producen por la extracción del metal tántalo (conocido por coltán), es más coincide hasta el área geográfica. Por ello, hubiera sido acertado seguir esta línea de actuación más inmediata y con un alcance mundial. Bien entendido, que para que tuviera la máxima potencialidad debería introducirse la evolución por la que se aboga en este estudio. De cualquier manera, el Procedimiento Kimberley puede seguir inspirando nuevas normativas.

La Unión Europea no aprovecha esa oportunidad respecto de los minerales y metales, y opta por aprobar el Reglamento de diamantes de conflicto, basado en la diligencia debida. Su marco de actuación está limitado a los conocidos por sus siglas en inglés $3 \mathrm{~T}+\mathrm{G}$. De nuevo, el sistema se queda corto, no acoge otros minerales estratégicos y no tiene un carácter mundial, con lo que puede contribuir a mitigar el problema, pero difícilmente podrá terminar con él. Dependiendo del éxito de su implantación, otra posible solución vendría dada por la aplicación de su ámbito de aplicación.

Otro posible enfoque llevaría a intentar diseñar una normativa mixta que se inspirase en el tejido estructural de ambas normativas. Sin embargo, la propia naturaleza de los mecanismos estudiados, no parece que haga factible esta opción. Kimberley se ancla en la prohibición de comercialización

60 Diago Diago «El comercio internacional de diamantes: Sistema de certificación del Proceso Kimberley», p. 91. 
con los países no participantes, lo que casa mal con el carácter voluntario, si se permite la expresión «benigno», del Reglamento de minerales de conflicto.

La cuarta idea enlazaría con la visión más ambiciosa del diseño de una solución de alcance mundial ${ }^{61}$. Se trataría de proyectar una normativa de carácter global que fuera aplicable a la comercialización de recursos naturales, cuya extracción genera conflictos que entrañan violaciones de Derechos Humanos ${ }^{62}$. Sin olvidar un problema que también acompaña a la extracción de esos recursos y que se refiere a las consecuencias lesivas para el medio ambiente y la destrucción de enclaves importantes desde el punto de vista cultural o ritual ${ }^{63}$.

Una normativa de este calado y de este alcance debería contar con un compromiso mayor que el de los Estados. Las industrias del sector deberían estar implicadas y ello es factible, si tenemos en cuenta el precedente de Kimberley con el sistema de autorregulación de la industria del diamante ${ }^{64}$. También debería contarse con la implicación de la sociedad civil y en especial, de los ciudadanos. La toma de conciencia de esa problemática, desde todos los sectores, resultaría vital para la consecución de los objetivos.

Precisamente, la implementación que cabria realizar respecto de las normativas de referencia y respecto del posible diseño de una normativa a nivel mundial, debería venir dada por la implicación directa del consumidor. En realidad, esta estrategia ya se ha ensayado, con éxito, por lo que se refiere a los diamantes en bruto.

La opinión pública no despierta a la realidad que rodea a los diamantes de conflicto con la reacción de Naciones Unidas, ni con el Procedimiento Kimberley. El detonante que lleva a un posicionamiento de la ciudadanía

${ }^{61}$ Diago Diago «El control del comercio internacional de los minerales de conflicto: Reglamento (UE) 2017/831 por el que se establecen obligaciones en materia de diligencia debida en la cadena de suministro de estaño, tántalo y wolframio, sus minerales y oro», último apartado.

62 En esta línea Vilar González «Iniciativas para la erradicación de los abusos de los derechos humanos asociados al negocio de las «minas de sangre» señala que «la Comunidad Internacional no debería descartar la adopción de un instrumento internacional, de carácter global, que fuera de aplicación en la comercialización de recursos minerales y metales con carácter general, en el que deberían estar implicados gobiernos, industria del sector, sociedad civil e, incluso, los ciudadanos particulares, que deberían alcanzar un notable grado de consciencia con respecto a la problemática asociada a las llamadas «minas de sangre» para, con ello, seguir avanzando en la erradicación o, cuanto menos, minimización de las consecuencias lesivas que estas prácticas suponen en los derechos humanos y en el medio ambiente» $\mathrm{p}$. 119.

${ }^{63}$ A esta problemática concreta se refiere el Reglamento de minerales en el Considerando 3 .

${ }^{64}$ V. Capítulo IV del Reglamento Kimberley art. 17 
fue la proyección de la película «Blood Diamond», protagonizado por Leonardo Di Caprio, Jennifer Connelly y Djimon Hounsou. Esta película está ambientada en Sierra Leona y describe el comercio de diamantes como fuente de financiación para la guerra, así como la violación de Derechos Humanos, desde la esclavitud, las torturas, mutilaciones, violaciones, hasta el asesinato.

El temor ante la reacción negativa de los consumidores, condujo al Consejo Mundial del diamante a intervenir. La estrategia que se desarrolló fue la de informar a los consumidores, a través de una campaña de publicidad que costo aproximadamente 15 millones de dólares, de la situación actual, en la que existen ya medios para impedir que los diamantes de sangre penetren en el mercado. Así es como se presentó Kimberley a la sociedad.

Por su parte Amnistía Internacional y Global Fitness, aprovechó la proyección de la película, para lanzar una campaña de información y concienciación sobre el problema real de los diamantes de sangre. Se solicitaba, en especial, a los consumidores que se informasen y que exigieran garantías antes de comprar un diamante.

La concienciación de los consumidores resulta vital para el desarrollo con éxito de los diferentes procedimientos. No debe olvidarse que el juego del prestigio de las empresas puede ser utilizado como un incentivo para su cumplimento en este marco. Pero a su vez, la creación de una, por llamarla así, «etiqueta responsable» justificaría un pequeño aumento del precio final.

La línea que se propone, tiene precedentes que se sitúan, por ejemplo, en las recomendaciones de los Confederación internacional de joyería (CIBJO) sobre el abastecimiento responsable. De hecho, hoy existe la joyería responsable y sostenible ${ }^{65}$. También cabe recordar la existencia del oro de minería justa ${ }^{66}$ e incluso, las normativas de etiquetado ecológico de los alimentos ${ }^{67}$.

En definitiva, la oportunidad de implicar a los consumidores se proyecta en dos ámbitos. El primero, es el de la información. El consumidor debe conocer que los productos que llegan a sus manos pueden estar relacionados con la violación de Derechos Humanos. El segundo, se relaciona con el trabajo realizado por la industria, en la ejecución de las buenas prácticas o diligencia debida. De manera que se debe poder ofrecer al consumidor la posibilidad de adquirir productos «libres de conflicto». Como ya se han indicado, esa «etiqueta responsable» puede justificar un aumento en el precio que compense el esfuerzo que las empresas realizan en este ámbito.

\footnotetext{
65 https://www.responsiblejewellery.com

${ }^{66} \mathrm{https} / / / \mathrm{www}$.fairmined.org/es/

${ }^{67} \mathrm{https} / / / \mathrm{www}$.ecoagricultor.com/etiquetado-de-los-alimentos-ecologicos/
} 


\section{Consideraciones finales}

La Unión Europea se encuentra en una posición optima para contribuir a la consecución de los objetivos de desarrollo sostenible y sus metas. Cuenta con dos normativas pioneras que se orientan a romper el triángulo siniestro que relaciona la extracción y comercialización de los diamantes y de los minerales con los conflictos, con las vulneraciones de los Derechos Humanos.

Ambas normativas utilizan mecanismos diferentes que han sido analizados exhaustivamente en este estudio. El Reglamento Kimberley apuesta por proteger el mercado legal de diamantes en bruto; lo hace a través del sistema de certificación y de las prohibiciones de exportar e importar diamantes que procedan de países no participantes. El resultado es la creación de un mercado legal de diamantes que deja fuera a los diamantes en conflicto.

Por su parte, el Reglamento de minerales de conflicto establece una serie de obligaciones en materia de diligencia debida en la cadena de suministro que recaen en los importadores de la Unión Europea y que se denomina sistema de la Unión. Su plena operatividad no se producirá hasta el 1 de enero del 2021, lo cual no ha sido impedimento para estudiar su estructura y sus mecanismos de actuación.

Como se ha tenido ocasión de demostrar, ambas normativas presentan fortalezas importantes y también debilidades. Se ha tratado de apuntar posibles soluciones de reforzamiento de estas últimas. No debe olvidarse que al margen de la importancia de la problemática que abordan, está el hecho de que ambas configuran una política comercial común de la Unión Europea. Esta política afecta directamente a las relaciones privadas internacionales y al comercio internacional. De ahí, que todas las vías de mejora sean necesarias, dado lo sensible que es para todos los agentes implicados, el establecimiento de un control sobre el comercio de los diamantes y de los minerales de conflicto.

Se ha realizado, por último, una prospección de soluciones jurídicas con especial atención a la implementación de los dos mecanismos. Esta debe venir dada por una implicación del consumidor final. El camino recorrido por la llamada joyería responsable puede ser un ejemplo a tomar en cuenta. El consumidor debe conocer que existen estos conflictos y que sus productos de consumo pueden relacionarse con violaciones de Derechos Humanos.

A su vez, debe poder acceder a productos finales con la «etiqueta responsable» «libre de conflicto» que justificaría un pequeño aumento del precio final del producto. A estos efectos, la reputación y el prestigio de las empresas también son herramientas para la consecución efectiva de los objetivos trazados por las normativas. 
En tiempos de objetivos de desarrollo sostenible, la proyección en la práctica de normativas que sean aptas para su consecución, adquiere protagonismo. Tanto los juristas como los agentes económicos, la sociedad civil y en especial, los consumidores debemos estar implicados en esta problemática. Los avances alcanzados y que se esperan alcanzar con ambos Reglamentos son notables, pero insuficientes. Podemos y debemos aunar esfuerzos para combatir las consecuencias que la explotación de los recursos naturales tiene sobre la vulneración de Derechos Humanos. La vida de las personas, la paz y la seguridad internacional bien lo vale.

\section{Sobre la autora}

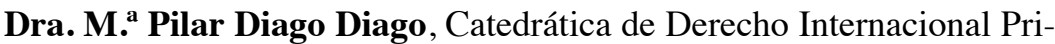
vado de la Universidad de Zaragoza, miembro de la Cátedra UNESCO sobre «Ciudadanía Democrática y Libertad Cultural (785)» y Vicepresidente de las Asociación de Profesores de Derecho Internacional y Relaciones internacionales. Es responsable editorial de la Revista científica Bitácora Millennium DIPr http://www.millenniumdipr.com/bitacora e informante de las principales publicaciones de su disciplina como REEI, REDI, AEDIPr o SYBIL. Es experta evaluadora de la Agencia Estatal de Investigación. Ha impartido conferencias científicas y ha participado como ponente y conferenciante en instituciones y eventos en España, Holanda, Marruecos, Italia, Brasil, Túnez, Suiza, Argelia, Portugal y Puerto Rico.

En el ámbito de la innovación docente ha acuñado el lema ¡Todo es Internacional! que inspira el apasionante proyecto Millennium DIPr. http://www.millenniumdipr.com, del cual es coordinadora. En este marco, el proyecto «el empleo de las Redes sociales y el cine en la enseñanza universitaria del S XXI» ha merecido el accésit al Premio Cátedra Santander en su XI Edición. Es colaboradora habitual de diferentes medios de difusión y trabaja como experta independiente en diversos organismos públicos y privados.

\section{About the author}

Dr. M. ${ }^{a}$ Pilar Diago Diago, Professor of Private International Law at the University of Zaragoza, member of the UNESCO Chair on «Democratic Citizenship and Cultural Freedom» (785) and Vice-President of the Association of Teachers of International Law and International Relations. Director of the scientific journal Bitácora Millennium DIPr http://www.millenniumdipr.com/bitacora evaluator of the main publications in her discipline such as REEI, REDI, 
AEDIPr or SYBIL. She is an expert of the State Research Agency. She has given scientific conferences and has participated as a speaker and lecturer in institutions and events in Spain, Holland, Morocco, Italy, Brazil, Tunisia, Switzerland, Algeria, Portugal and Puerto Rico.

She has coined the motto Everything is International! which inspires the exciting Millennium DIPr project http://www.millenniumdipr.com of which she is the coordinator. Within this framework, the project «The use of social networks and cinema in university education in the 21 st century» has been awarded the 11th edition of the Santander Chair Award. She is a regular contributor to different media and works as an independent expert in various public and private organizations. 


\section{Derechos de autor}

Los derechos de autor (para la distribución, comunicación pública, reproducción e inclusión en bases de datos de indexación y repositorios institucionales) de esta publicación (Cuadernos Europeos de Deusto, CED) pertenecen a la editorial Universidad de Deusto. El acceso al contenido digital de cualquier número de Cuadernos Europeos de Deusto es gratuito inmediatamente después de su publicación. Los trabajos podrán leerse, descargarse, copiar y difundir en cualquier medio sin fines comerciales y según lo previsto por la ley; sin la previa autorización de la Editorial (Universidad de Deusto) o el autor. Así mismo, los trabajos editados en CED pueden ser publicados con posterioridad en otros medios o revistas, siempre que el autor indique con claridad y en la primera nota a pie de página que el trabajo se publicó por primera vez en CED, con indicación del número, año, páginas y DOI (si procede). Cualquier otro uso de su contenido en cualquier medio o formato, ahora conocido o desarrollado en el futuro, requiere el permiso previo por escrito del titular de los derechos de autor.

\section{Copyright}

Copyright (for distribution, public communication, reproduction and inclusion in indexation databases and institutional repositories) of this publication (Cuadernos Europeos de Deusto, CED) belongs to the publisher University of Deusto. Access to the digital content of any Issue of Cuadernos Europeos de Deusto is free upon its publication. The content can be read, downloaded, copied, and distributed freely in any medium only for non-commercial purposes and in accordance with any applicable copyright legislation, without prior permission from the copyright holder (University of Deusto) or the author. Thus, the content of CED can be subsequently published in other media or journals, as long as the author clearly indicates in the first footnote that the work was published in CED for the first time, indicating the Issue number, year, pages, and DOI (if applicable). Any other use of its content in any medium or format, now known or developed in the future, requires prior written permission of the copyright holder. 